\title{
Network structure and institutional complexity in an ecology of water management games
}

\author{
Mark Lubell ${ }^{1}$, Garry Robins ${ }^{2}$ and Peng Wang $^{2}$
}

\begin{abstract}
Social-ecological systems are governed by a complex of ecology of games featuring multiple actors, policy institutions, and issues, and not just single institutions operating in isolation. We update Long's (1958) ecology of games to analyze the coordinating roles of actors and institutions in the context of the ecology of water management games in San Francisco Bay, California. The ecology of games is operationalized as a bipartite network with actors participating in institutions, and exponential random graph models are used to test hypotheses about the structural features of the network. We found that policy coordination is facilitated mostly by federal and state agencies and collaborative institutions that span geographic boundaries. Network configurations associated with closure show the most significant departures from the predicted model values, consistent with the Berardo and Scholz (2010) "risk hypothesis" that closure is important for solving cooperation problems.
\end{abstract}

Key Words: complex adaptive systems; cooperation; ecology of games; institutions; resilience

\section{INTRODUCTION}

Institutional complexity is a defining feature of governance in social-ecological systems (SESs) and other policy arenas (Folke et al. 2005, Teisman and Klijn 2008). For example, our empirical study demonstrates that water governance in San Francisco Bay (SF Bay), California features more than 100 different policy institutions operating simultaneously. The diverse mix of institutions includes collaborative partnerships, permitting processes, local and regional planning, interest group associations, and joint powers authorities. This system of institutions is addressing multiple collective-action problems such as water supply, water quality, flooding, climate change, and biodiversity. SF Bay is not unique among environmental policy settings, and such institutional complexity exists in many substantive policy domains. Institutional complexity is not a hypothesis; it is the everyday reality faced by policy-makers and resource users in SESs throughout the world.

We describe a theoretical and methodological approach for analyzing complex institutional systems, and develop hypotheses about how the structural properties of the system relate to coordination and cooperation. From the theoretical perspective, we update the "ecology of games" (EG) concept first coined by Norton Long (1958) and employed in a few other studies (Dutton 1995, Cornwell et al. 2003, van Bueren et al. 2003, Lubell et al. 2010, Lubell 2013). As with the related idea of "linked action situations" (Kimmich 2013, McGinnis 2011), our approach builds on Ostrom's (2009b) institutional analysis and development (IAD) framework and its extension to the institutional analysis of SESs (Anderies et al. 2004, Ostrom 2009a).

Our version of the EG framework argues governance constitutes multiple policy games operating simultaneously within a geographically defined policy arena (Lubell 2013). A policy game consists of a set of policy actors participating in a rule-governed, collective-choice process called a "policy institution,"[1], where each policy institution has jurisdiction over one or more collective-action problems (e.g., public goods, comon pool resources). Actors participate in different institutions in order to influence the policies governing the different problems, which real-world policy actors usually call "policy issues." As with the IAD framework, we assume actors seek to solve collective-action problems and use political power to bargain over the resulting resource gains (Knight 1992, Moe 2005). The ensuing constellation of actors, issues, and institutions constitutes a complex adaptive system (Levin 1998, 2002) that evolves over time in a particular geographic region.

A crucial question in such complex and fragmented systems is how policies are coordinated over time. While the broad literature on SES governance frequently discusses the importance of coordination and collaboration (Folke et al. 2005, Lebel et al. 2006, Armitage et al. 2008), exactly how it is achieved in the context of complex institutional arrangements remains underdeveloped. We empirically test four complementary hypotheses about how the structure of the water management EG in SF Bay reflects different mechanisms for coordinating governance and policy activities. First, the "actor hypothesis" suggests that actors with access to resources like political authority, expertise/information, broad geographic scope, and finances have a greater capacity to coordinate policies and influence outcomes in the EG (Scharpf 1997). Within the United States, these resources tend to be concentrated in the hands of government agencies, particularly at the state and federal level. Government agencies are delegated political authority by higher level political decisions, collect data and scientific research to support their decision-making, hire employees with specialized expertise, and shape incentives with financial resources like grant programs.

Second, the "institutions hypothesis" argues that institutions are embedded in governance structures in ways that reflect their overall role in providing incentives for cooperation (North 1990, Ostrom 1990, Scharpf 1997). We are particularly interested in collaborative institutions, which emphasize specific types of rules: inclusive participation of multiple stakeholders, consensus

${ }^{1}$ Department of Environmental Science and Policy, University of California Davis, Center for Environmental Policy and Behavior, ${ }^{2}$ University of Melbourne 
decision-making, integration of scientific information, voluntary implementation, and place-based activities (Lubell 2004). Proponents argue collaborative institutions reduce the transaction costs of cooperation in the context of complex and diffuse environmental problems like water management.

Third, we explore Berardo and Scholz's (2010) "risk hypothesis" that the structure of policy networks reflects the types of collective-action problems they evolve to solve. The risk hypothesis distinguishes between cooperation games where mutual cooperation is not an equilibrium because there is a temptation to free ride (defect), versus assurance games where mutual cooperation is an equilibrium as long as all players expect others to play the same strategy. ${ }^{[2]}$ Risk in this setting refers to the strength of the free-riding incentive, which is highest in Prisoner's Dilemma types of settings. The EG framework assumes that actors are facing some mixture of these types of games, with the caveat that we cannot directly measure the payoffs in our empirical application. Berardo and Scholz (2010) also do not directly measure the payoffs in the underlying games, but rather rely on the observed structure of the network to infer what types of games are being played.

According to the risk hypothesis, the benefits of different policy network configurations are a function of the types of underlying games. When the policy ecology consists mainly of assurance games, policy networks are centralized around actors and institutions that function as policy brokers to more efficiently transmit information and assurance about which strategies others will choose. The centralized systems feature more "open" network structures where the marginal benefits of spreading additional information are less than the costs of maintaining redundant ties. When the policy ecology consists of risky cooperation games with free-riding incentives, actors prefer "closed" network structures where redundant ties provide an ability to conditionally cooperate and sanction other actors on the basis of reputation and history of interaction. It is important to note that we expect actors, institutions, and network configurations to operate as complementary, not competing, mechanisms for facilitating collective-action within the EG (Breiger 1974).

Fourth, the "geographic constraint hypothesis" argues that actors located within a particular geographic region are more likely to participate in the same institutions. Geographic constraints are implicit in SES frameworks, where biophysical processes linked at local scales like watersheds create incentives for social linkages between actors who use the associated resources (Bodin and Tengö 2012). Physical proximity also increases the likelihood of repeated interaction and network formation (Gerber et al. 2013). But the tendency of geography to favor local network formation creates challenges for cross-scale learning and regional coordination, creating a role for governance actors and institutions with broad geographic scope to share information and account for interdependencies at multiple scales.

The EG framework connects the IAD and SES literatures by analyzing the structure and function of complex institutional systems that govern SESs. The EG framework scales-up to consider the "complexities of multi-party and multi-scaled governance" (Armitage et al. 2008). A common criticism of IAD is the focus on single common-pool resource problems like a local fishery or forest, where relatively homogenous sets of users are governed by a single set of institutional rules. However, many important SESs operate at the ecosystem level, where the idea of ecosystem management requires consideration of the interactions between many different common-pool resource and public goods problems. We focus specifically on the challenge of policy coordination, which is particularly acute in complex institutional systems where decisions made in one institution can have positive or negative spillovers for other institutions (Lubell 2013).

By considering multiple collective-action problems and institutions, the EG framework extends the idea of polycentric governance (Ostrom et al. 1961), which is a long-standing theme in the SES literature (Lebel et al. 2006). Ostrom (1994:225) defines a polycentric system as a self-organizing system composed of "(1) many autonomous units formally independent of one another, (2) choosing to act in ways that take into account of others, and (3) through processes of cooperation, competition, conflict, and conflict resolution." The EG framework develops empirically testable hypotheses about the structure and function of polycentric governance systems, where many diverse institutions operate to shape individual behavior. For example, Ostrom et al. (1961) discuss how higher level institutions mitigate conflict when local decisions generate regional externalities. We provide some empirical evidence that higher level institutions and actors are more active in governance networks after controlling for local geographic constraints.

Recognizing the existence of multiple institutions also provides a new perspective on theories of collaborative governance (Sabatier et al. 2005, Koontz and Thomas 2006, O'Leary et al. 2006, Ansell and Gash 2008). Instead of focusing on the internal dynamics of cooperation within an individual collaborative institution, the EG framework adopts a system perspective that emphasizes how multiple collaborative institutions co-exist with many other types of institutions, including command-and-control regulatory processes. For example, there is a large literature on the effectiveness of CALFED, which from 1984 to 2009 was one of the most prominent examples of collaborative institutions in the SF Bay region (Kallis et al. 2009, Booher and Innes 2010, Lubell et al. 2013). Rather than focusing on CALFED's internal dynamics, the EG framework examines whether CALFED and other collaborative institutions are structurally embedded in networks in ways that are consistent with their goal of policy coordination. Furthermore, the dynamic aspect of the theory considers how different collaborative institutions might emerge and decline over time. In the case of SF Bay, qualitative data suggest the "death" of CALFED set the stage for the next period of system evolution featuring the emergence of new institutions like the Bay Delta Stewardship Council and the Bay Delta Conservation Plan.

We also contribute to the literature on network governance in SESs, which has focused primarily on unipartite (one mode) networks of some type of social relationship among individuals or organizations (Jones et al. 1997, O'Toole 1997, Schneider et al. 2003, Carlson and Sandstrom 2008, Bodin and Crona 2009, Kenis and Provan 2009, Robins et al. 2011). One important problem with the SES network governance literature is that there is not a consensus on what types of network structures are more effective for different types of social-ecological contexts (Bodin and Crona 2009). Furthermore, the SES network governance literature is just 
beginning to explore how network relationships among actors are constrained by institutional or ecological factors at different levels. We contribute to this latter concern from both a theoretical and methodological perspective.

From a theoretical perspective, we focus on how different types of institutions structure the overall patterns of coordination and collaboration among SES actors. The EG framework argues not only that most SESs involve a set of complex institutions, but also that specific institutions and actors that are central in the complex system have more influence on overall coordination. Our hypotheses speak to the characteristics of institutions and actors that are most important for coordination across governance networks. For example, at least in Western developed countries, the emergence of collaborative institutions can be considered an adaptive response to addressing problems of fragmentation in complex systems. Although we do not provide a rich conceptualization of the structure of the ecological system, our geographic constraint hypothesis does imply interdependence between the social and ecological parts of the system.

On the methodological front, testing these types of hypotheses requires network analysis models that account for interactions between social and ecological entities at different levels. We operationalize the EG as a bipartite network (also called twomode network) defined by actors (mode 1) participating in institutions (mode 2), and test our structural hypotheses using exponential random graph models (ERGMs) that estimate the probability of network tie formation as a function of different structural characteristics of the network and attributes of actors and institutions (Wang et al. 2009, Cranmer and Desmarias 2011, Lusher et al. 2013). The bipartite representation is important because it explicitly captures the relationships between institutions and actors, whereas one-mode networks of relationships between actors only implicitly consider the role of institutions.

Furthermore, analyzing the multinode structure of SESs is consistent with emerging research and methods on multilevel networks (Wang et al. 2013). These new network methods open the possibility of a simultaneous examination of both ecological and social systems, and the cross-level connections between them (Bodin and Tengö 2012). Empirical approaches that explicitly consider multiple components of complex systems are the key to future progress in the analysis of SESs. We see the current work on multilevel governance as part of this new conceptualization, and future work should seek to explicitly link complex institutional systems to the ecological level with dependence among ecological units.

\section{REPRESENTING THE ECOLOGY OF GAMES AS A BIPARTITE NETWORK}

The San Francisco Bay water management EG can be represented as a bipartite network where network links are defined by policy actors participating in one or more policy institutions. The assumption is that actors make participation decisions given the current set of available institutions, although the dynamic creation and destruction of institutions is possible. The bipartite representation is admittedly a simplification that does not capture all of the theoretical building blocks of the EG framework (see Lubell 2013 for extended discussion). For instance, we do not explicitly analyze how institutions, actor populations, and patterns of participation change over time; like any cross-sectional data, our analysis captures a snapshot of a dynamic process. However, bipartite networks do capture a level of complexity and interdependence that is not typically considered in analyses of single policy actors or institutions in isolation.

We investigate three network processes that are likely to structure the EG: network activity, network centralization (which is linked to degree dispersion or variance), and network closure (Fig. 1). These three network processes have been discussed extensively in the analysis of unipartite (e.g., actor-to-actor) networks (Snijders et al. 2006), but less so for bipartite (e.g., actor-to-institution) networks (Berardo 2014). Each process can be associated with observable network configurations. Network configurations are small patterns

Fig. 1. Bipartite network configurations.

Basic Configurations for Network Activity

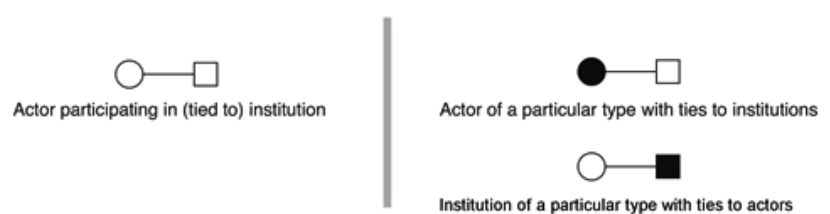

Basic Configurations for Network Centralization

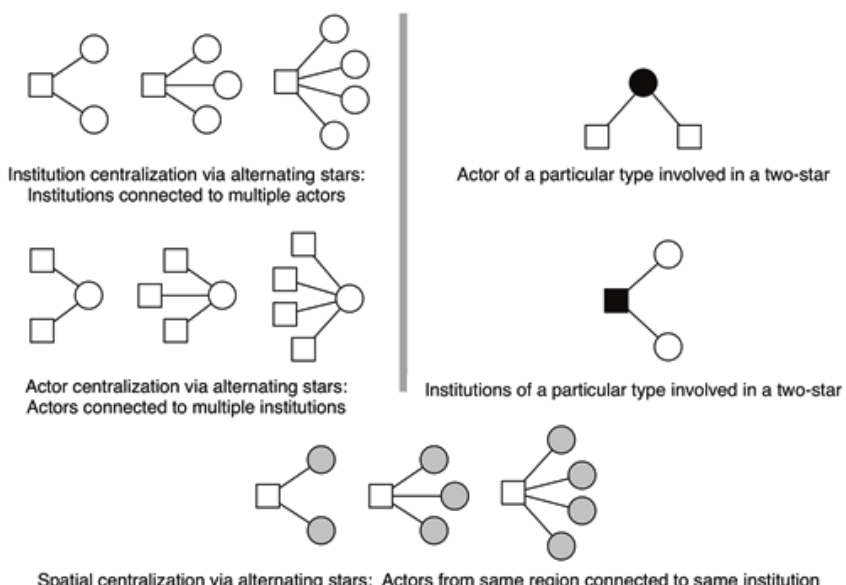

Basic Configurations for Network Closure

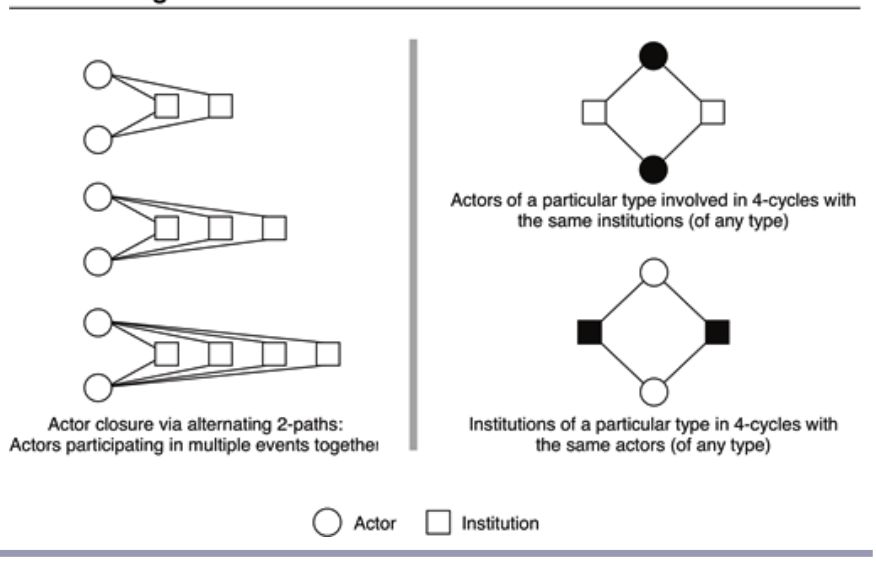


of ties within the graph or subgraphs, which are sometimes referred to as network motifs (Milo et al. 2002). If a particular configuration is a likely outcome of a social process occurring within the network, that configuration will occur at a higher frequency in the observed network than expected by chance once other possibly relevant processes are controlled. The term "chance" in this context refers to the expected frequency of network configurations under different "null" statistical models of the network representing different assumptions about the strategic behavior of policy actors.

\section{Network activity}

The number of ties a node has can be interpreted broadly as a measure of network activity; network analysis typically refers to this as the degree of a node. The top, left panel of Fig. 1 shows the configurations associated with general network activity in a bipartite graph for the overall frequency of ties irrespective of actor/institution types.

The right, top panel of Fig. 1 shows a configuration of an actor of a particular type having a tie to an institution (of any type), where a particular type is treated as a binary variable and is represented by the filled black circle in the figure. If that type of actor is more active than others in the network, we will see more of these configurations than expected controlling for the general level of network activity. For instance, if the filled square represented federal government agencies, and if these agencies exhibited more network activity than other types of actors, then we would see relatively more of these federal government configurations in the data. Conversely, an institution of a specific type (filled black square) may have ties to actors of any type.

\section{Network centralization}

Network activity may be distributed in different ways. Each node could have a relatively similar number of ties, or some nodes could have a very high number of ties, while other nodes have relatively few. More centralized networks have high levels of activity around a small number of central actors and institutions. This plays out as higher variance for the distribution of degrees across the nodes, or in other words, higher degree dispersion.

Network centralization and degree dispersion are represented by star configurations, where a node has connections to multiple other nodes, as in Fig. 1. The left, middle panel of Fig. 1 shows 2-, 3-, and 4-star configurations that represent the degree distributions for both actors and institutions. The standard way to treat these configurations in ERGMs is to combine them into the one parameter for each degree distribution (Snijders et al. 2006, Wang et al. 2009), the so-called alternating star parameter. ${ }^{[3]}$ A positive alternating star parameter indicates a higher dispersion in the degree distribution and hence a more centralized network. A negative parameter indicates a degree distribution without great variation among nodes.

The right, middle panel column of Fig. 1 depicts 2-star configurations with actors and institutions of a particular type at the center of the star. These configurations represent withincategory centralization that occurs over and above tendencies for centralization captured by the general alternating star parameter. For a given level of network activity, the presence of more 2-stars indicates a more centralized network structure based around a particular type of actor (e.g., federal government agencies) or institution (e.g., collaborative institution).
The middle, central panel of Fig. 1 displays spatial star configurations centered on institutions that involve actors from the same geographic region. We combine these different stars into an alternating star parameter to represent geographic centralization, which can be interpreted as a form of geospatial homophily where actors from the same region play similar games. This is a novel parameter in bipartite ERGMs and has been specially incorporated into our models to test the geographic constraint hypothesis.

\section{Network closure}

Network closure has been discussed extensively for unipartite social networks and is widely observed empirically. Network closure occurs in unipartite networks when a network path from actors $i$ to $j$ to $k$ is closed into a triangle configuration by an additional tie between $k$ and $i$. Discussions of network closure extend back to Simmel (1908), and have remained a major theme in network theory since the work of Granovetter (1973) and Burt (1992), both of whom considered how closed versus open network structures influence an individual's access to social resources.

Unipartite network closure can arise because individuals introduce acquaintances to each other, because people with similar interests, concerns, or pressures come into the same social environment, or because people tend to operate in team-like, collaborative structures. There are various likely outcomes: these closed structures can enhance social support and cooperation, they permit closer scrutiny of actions, and they may lead to stronger group norms or localized cultures. Closed structures provide the security of redundancy (more ties are used than necessary to provide connection between actors), but may inhibit the flow of new information or innovation (Berardo and Scholz 2010). Network closure involves a trade-off between processes that benefit from coherence and reputation, versus the efficiency of information that comes from a multiplicity of nonredundant ties.

Bipartite networks require an extension to the notion of closure beyond the triadic configurations, the simplest of which are the cyclic structures displayed in the bottom panel of Fig. 1. The left, bottom panel depicts 2-paths between pairs of actors participating in the same two, three, and four institutions. Analogous to the star parameters, these configurations are combined into one alternating 2-path parameter to represent general bipartite network closure for actors. A positive parameter indicates a tendency for actors to share institutions to create denser regions of the network, whereas a negative parameter indicates the opposite, suggesting brokerage activities across the network as at least some actors tend to participate beyond a small number of shared institutions. With the alternating 2-path parameter in the model, closure for specific types of actors and institutions can be represented by simple 4-cycles, as depicted on the right, bottom panel of the figure. The specific actor 4-cycle represents actors of a particular type (e.g., federal agencies) participating in the same institutions, while specific institution 4cycles represent institutions of the same type attracting similar sets of actors.

Analogous to the unipartite arguments above, bipartite closure represents a more cohesive, collaborative structure, but possibly with costs in terms of overlap and redundancy. A high number of 4-cycles relative to network activity suggests tendencies for closure, while a lower than expected level of closure indicates 
network brokerage where actors are connected through institutions to other actors who are participating in different institutions.

\section{Summary of specific network structure hypotheses}

The extent to which the above processes characterize the structure of the network, and how they are associated with particular types of actors or institutions, provides tests of our main hypotheses. The actor hypothesis argues that federal and state agencies, with their capacity and resources for coordination, should have the highest levels of activity, centralization, and closure within the overall network. The institutions hypothesis posits that due to institutional rules encouraging inclusive participation along with the specific goal of promoting cooperation among diverse actors, collaborative institutions will have the highest levels of activity, centralization, and closure within the network. The geographic constraint hypothesis suggests that actors within the same geographic region will participate in the same policy institutions.

Translated into the context of bipartite networks, Berardo and Scholz's (2010) risk hypothesis suggests efficient information transmission in coordination games is facilitated by networks that feature high levels of activity and degree dispersion centralized around a small number of nodes. Bipartite networks with high levels of closure provide more redundant links, which can help solve risky cooperation problems by providing opportunities for conditional cooperation, sanctions, and reputation building. This implies that specific types of actors and institutions function to solve cooperation problems if they are embedded in a high number of 4-cycles, and again, we expect state and federal government agencies and collaborative institutions to serve this role. If these same types of actors and institutions are more involved with coordination problems and information transmission, they would also be associated with centralization structures.

Berardo and Scholz (2010) suggest a potential trade-off between centralization and closure, depending on the type of underlying collective-action problems. If this is true, then we expect centralization and closure processes to have opposite signs. At the global network level, a network that emphasizes centralization would tend to have a "core" anchored by a small set of central actors and institutions and few cohesive subgroups. A network that emphasizes closure would tend to have a greater number of cohesive subgroups, with fewer dominant central actors and institutions (less skewed degree distributions). However, it is also possible for there to be synergy between centralization and closure, where the overall system must simultaneously manage coordination and cooperation problems. In this case, we would expect to see centralization and closure operating simultaneously, with the global structure of the network appearing "polycentric" with multiple cohesive subgroups anchored by central institutions and actors.

\section{METHODS}

\section{Study design: the ecology of water management games in San Francisco Bay, California}

SF Bay is one of the most important coastal regions on the west coast of North America, and involves numerous environmental issues, actors, and policy institutions (Norgaard et al. 2009). The environmental issues include water supply, flood control, climate change adaptation, water quality, and biodiversity. Federal and state agencies have consistently played important roles in governing these issues, with the U.S. Environmental Protection Agency (EPA), U.S. Fish and Wildlife Service, California Department of Fish and Game, ${ }^{[4]}$ California Department of Water Resources, and California State/Regional Water Resources Control Boards as the central actors. But the cast of actors also includes local governments, special districts for water management, special districts for environmental management (e.g., open space), environmental groups, economic interest groups, and scientists.

Like in many other watersheds, the policy ecology of SF Bay is constantly evolving and has most recently experienced the emergence of a number of collaborative institutions. The most famous collaborative institution is the CALFED Bay-Delta Program, which emerged from a 1984 agreement between California and the EPA, and evolved to encompass the entire SF Bay-Delta watershed. Interestingly, the CALFED Bay-Delta Program was in decline when our data were collected, and was completely dismantled in 2010, to be replaced by the Delta Stewardship Council. Another important example, the Bay Area Integrated Regional Water Management Plan (IRWMP), was first initiated in 2005 as part of the state of California's primary strategy for building regional cooperation. But the point of our analysis is to recognize that multiple collaborative institutions exist at the same time in the Bay Area.

\section{Bay Area survey: eliciting the bipartite network}

The survey identified actors involved with SF Bay water management by first culling the list of participants from the IRWMP public meetings, outreach workshops, and implementation projects. Because IRWMP is one of the newest and most inclusive collaborative institutions in the SF Bay area, this provided a good starting point for the sample. Contact people were identified for each partner organization through web searches or by emailing or calling the organizations directly. A small number of respondents were added to the list via nominations from previous stakeholder interviews. We also cross-checked the list with a centralized database of water-related environmental impact reports in the region. The survey was reviewed by a number of different SF Bay stakeholders with whom the lead author has regular interactions; these stakeholders also provided a variety of qualitative insights about SF Bay water management. The survey was administered in April/May 2008 via a mixed-mode Dillman method (Dillman 2000). In total, 167 responses were received (157 via Internet, 10 via telephone), for a response rate of $50.8 \%$.

To identify the range of policy institutions in which actors were involved, we used a variant of a name-generator network question with the following wording:

"There are many different forums and processes available for participating in water management and planning in the Bay Area. Planning processes are defined as forums where stakeholders make decisions about water management policies, projects, and funding. In the spaces below, please list the most important planning/ management forums and/or processes that you yourself have participated in during the last three years. Please be as specific as possible with the name of the process."

The policy institution question was designed to identify what Ostrom (1999) would call the "collective choice"level of governance 
institutions in the Bay Area. The question wording attempted to translate the policy theory jargon of "collective-choice rules" into the policy vernacular of "processes," "forums," and "venues." These basic terms were accompanied by a brief description of the type of decision-making and management functions we were looking for. In general, we tried to avoid "constitutional" level institutions like the courts, legislature, and governor's office, and none of the respondents mentioned these institutions. We also tried to avoid the "operational" level of institutions, where specific decisions are being made about how to harvest resources and build infrastructure projects. As discussed in Alston (1996), it is important to hold some levels of a nested institutional structure constant to examine the dynamics at other levels.

The survey provided space for respondents to nominate up to three policy institutions, and then for each nominated institution, a "hybrid name generator" (Henry et al. 2012) asked the respondent to write in their collaboration partners in that institution from the categories of federal agencies, state government agencies, local/regional agencies, and private/ nonprofit actors. In other words, respondents not only reported about the activity of their own organization but also about other participants in the same institution. Of the 167 respondents who answered the survey, 70 (41.92\%) did not answer these questions, $13(7.78 \%)$ nominated one institution, $21(12.57 \%)$ nominated two, and $63(37.72 \%)$ nominated three. Hence, $58 \%(97 / 167)$ of the respondents identified at least one policy institution, and most of these identified the requested three institutions. The hybrid name generator mitigates response rate issues because it allows respondents to report on the range of involved actors without the necessity to survey a respondent from every single actor organization. ${ }^{[5]}$ Hence, the network data included 387 total actors, including the organizations of the primary respondents and actors nominated via the hybrid name generator.

The data were assembled into a bipartite network where each nominated policy institution was associated with the respondent's organization, plus any actors nominated via the hybrid name generator. The links represent actors participating in institutions; these are undirected links because only the actors are reporting behavior. The actor and institution types (Fig. 2) were coded by the researchers on the basis of Internet searches. Two codes that are not straightforward are "actor as venue," which refers to a respondent mentioning a particular agency (e.g., U.S. EPA) as a venue where important policy decisions are made, and "actor coalition," which refers to a coalition of actors that sometimes overlaps with the planning processes elicited in the policy institutions question.

Using actor websites, we manually coded actors into geospatial regions based mostly on county boundaries. A few actors spanned multiple counties and thus were given subregional designations like "East Bay" and "South Bay," which are nomenclatures commonly used throughout the region. The regional coding was used in the ERGMs to designate a geographical clustering parameter. Actors with statewide jurisdiction, such as the California Department of Water Resources, were excluded from geographical clustering because they cannot logically cluster at the subregional level.

\section{Exponential random graph models}

Exponential random graph models are statistical models of networks that explicitly posit a set of interdependent network processes that give rise to an observed network structure (Robins et al. 2007a, $b$ ). The observed network structure (in this case, the SF Bay bipartite network) is viewed as one possible outcome of these stochastic network processes. The localized network configurations (Fig. 1) between actors and institutions can (loosely) be understood as the independent variables in the model. The parameters for these independent variables yield a probability distribution of networks from which our observed network (the dependent variable) is drawn. The analysis assumes that the structure of the network will be consistent with the social processes outlined by our hypotheses. However, without directly observing those underlying social processes, we cannot completely rule out other causal explanations for the observed network structure.

Fig. 2. Bipartite network for the Bay Area ecology of games.

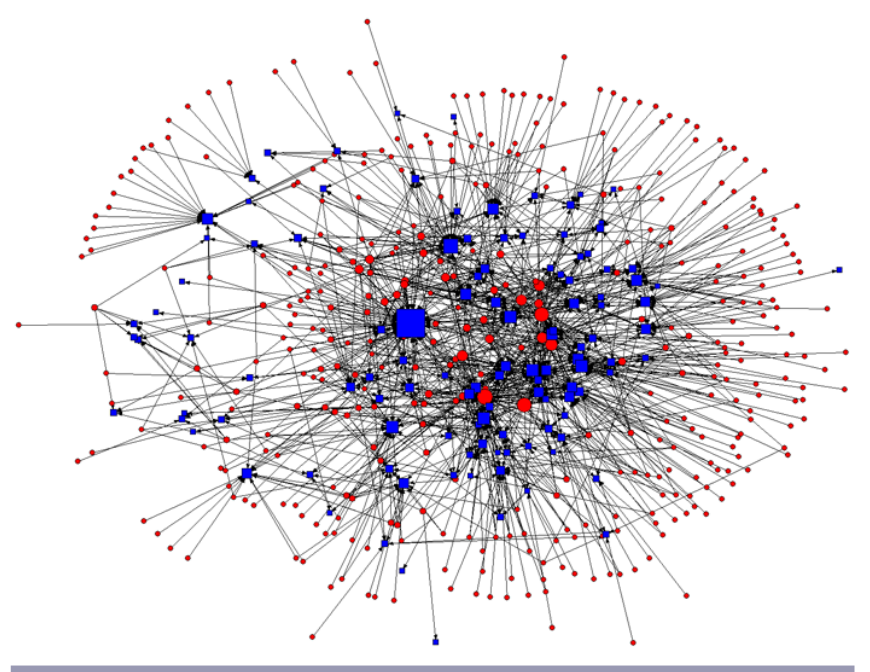

ERGMs are appropriate for analysis of cross-sectional network data and have some similarities to traditional regression or logistic regression approaches of regular survey sample data. As with any cross-sectional analysis, ERGMs capture only a snapshot of a dynamic social process. However, the network parameters estimated by ERGMs can be conceptualized as describing the cumulative results of a process of network formation that has been operating over time (Lusher et al. 2013). While the EG theory is explicitly dynamic, a cross-sectional analysis provides important initial insight, especially when coupled with substantive knowledge about policy change. As with other social research, longitudinal data collected in future studies will provide the opportunity for stronger tests of a broader range of hypotheses.

Table 1 describes a series of nested models representing different assumptions about political behavior in the EG, and including different sets of parameters from Fig. 1. The naïve actor model suggests that participation decisions are uniformly distributed across actors and institutions without regard to the capacity of different actors or the benefits available in any institution. It includes only the general network activity parameter in Fig. 1, 
Table 1. Hierarchy of exponential random graph models (ERGMs).

Naïve actor model (Bernoulli model): The observed probability of tie is fixed, and connections are then probabilistically distributed across each graph in the distribution. This model is equivalent to an ErdosRenyi model, or Bernoulli random graph distribution, in unipartite network analysis. It is analogous to a one-parameter log-linear or logistic regression model; it predicts the presence or absence of an agency-institution connection. The single ERGM parameter is called the density parameter.

Political capacity model (Bernoulli with node attributes): This is the naïve actor model with the addition of parameters that control for the activity of different types of actors and institutions. This model is analogous to a logistic regression model; it predicts the presence of absence of an actor-institution connection, with actor and institutional type as dummy variables representing difference in average degree relative to a baseline.

Strategic decisions model (Structural model with attributes): This is the political capacity model with the addition of parameters that control for centralization of both actors and institutions, and for closure attributable to actor type. The additional parameters are the agency and institution alternating k-stars and actor alternating k-2paths described by Wang et al. (2009). See Figs. 2 and 3 and associated text for further details.

Strategic geography model (Structural model with attributes and geographic centralization): This is the strategic decisions model with the addition of a spatial centralization parameter, an alternating geography k-star parameter that indicates actors from a similar geospatial region participate in the same popular institutions. See Fig. 2.

where a negative (positive) parameter indicates a rate of tie formation less (greater) than a 50\% chance of forming any particular tie.

The political capacity model includes a series of dummy variables for each type of actor and institution, with excluded variables for local government actors and collaborative institutions. The parameter estimates for the dummy variables capture whether the level of network activity is higher or lower for each type of institution or actor, relative to the baseline. The actor hypothesis suggests that state and federal agencies with higher levels of political capacity should have positive activity parameters, while the institutions hypothesis predicts that collaborative institutions should have positive activity parameters due to inclusive rules that encourage participation from many actors.

The strategic decisions model implies that actors have preferences over more complex network structures, and participation decisions are interdependent and strategic. According to the risk hypothesis, positive star parameters indicate a centralized network that makes coordination and information transmission more efficient, while a positive closure parameter suggests that actors are participating in institutions to solve cooperation problems. Therefore, this model predicts an alternating 2-star parameter (centralization) for actors and institutions and the alternating 2-path parameter (closure) for actors. ${ }^{[6]}$
The strategic geography model adds the geographic centralization parameter (bottom of middle panel in Fig. 2) and implies that opportunities for strategic interaction are constrained by the spatially explicit nature of environmental collective-action problems. The geographic centralization parameter controls for spatial clustering of actors: a positive parameter suggests that actors within the same region tend to play the same popular games.

After fitting each model and interpreting parameter estimates, we examine residual structural effects. Each model can be conceptualized as a "null hypothesis" that generates a distribution of network statistics that can be compared to the observed network. From a sample of graphs from the distribution, we then count the number of ties, 2-stars, and 4-cycles of different types (e.g., federal government agency 4-cycles), compare them to the observed counts in the data, and draw further inferences. For example, if the count of a particular type of 4-cycle in the data (for example, those involving federal agencies) is "extreme" compared to the distribution of 4-cycles arising from the simulation of graphs under a particular null model, we can infer a particular process of network structure (in this case, closure among federal agencies) not captured by the parameters of the model. If it is not extreme, then the number of 4-cycles is explained by the parameters of the model.

Following standard null hypothesis criteria, an "extreme" value in the residual analysis occurs if the observed data have more or less of a particular configuration than $95 \%$ of graphs from the simulation. The means and standard deviations for each type of configuration provide the basis for calculating a $t$ statistic for the observed data; a $t$ statistic $>2$ in absolute value indicates the observed data are extreme in comparison to the null distribution.

Interpreting model parameters in conjunction with residual analysis is necessary when a more complex, well-fitting model has difficulties producing converged maximum likelihood estimates (Wang et al. 2009). A full model would contain more than 50 parameters, including structural effects, as proposed by Wang et al. (2009), as well as three parameters (activity, dispersion, closure) for each of 10 types of actors and six institution types, and spatial parameters for 16 types of actors/institutions. The novelty of our approach is to apply the Pattison et al. (2000) strategy of a hierarchy of null models to sharpen inference for bipartite networks. This strategy goes beyond other network studies (Bearman et al. 2004, Baldassarri and Diani 2007) that simply compare the observed network statistic to the "naïe actor" model because we attempt to build more complexity and different assumptions about policy decisions into each stage of model building.

\section{RESULTS}

Fig. 2 displays a "spring-embedding" visualization of the entire Bay Area ecology of games network, and Fig. 3 zooms into the most central actors and institutions that have a degree (number of connections) of 16 or greater. The red circles represent actors, while the blue squares represent institutions. The size of the shapes is scaled to the degree of the node.

Fig. 4 displays "fat-tail" degree distributions characterized by a large number of nodes with small numbers of ties, but with a small number of nodes with high numbers of ties. For actors, the modal observed number of connections is 1 , with median degree of 1 
and an average of degree 3.09. For institutions, the modal degree is 5 , with a median degree of 7 and an average degree of 10.33 (without the IRWMP institutional node, the average is still 9.66.) The mean degree for institutions is significantly higher than for actors $(t$ test $=11.67$; reject null hypothesis of difference $=0 ; p<$ 0.01 ), which suggests that the network is more clustered around institutions than actors.

Fig. 3. Most central actors and institutions in the Bay Area ecology of games.

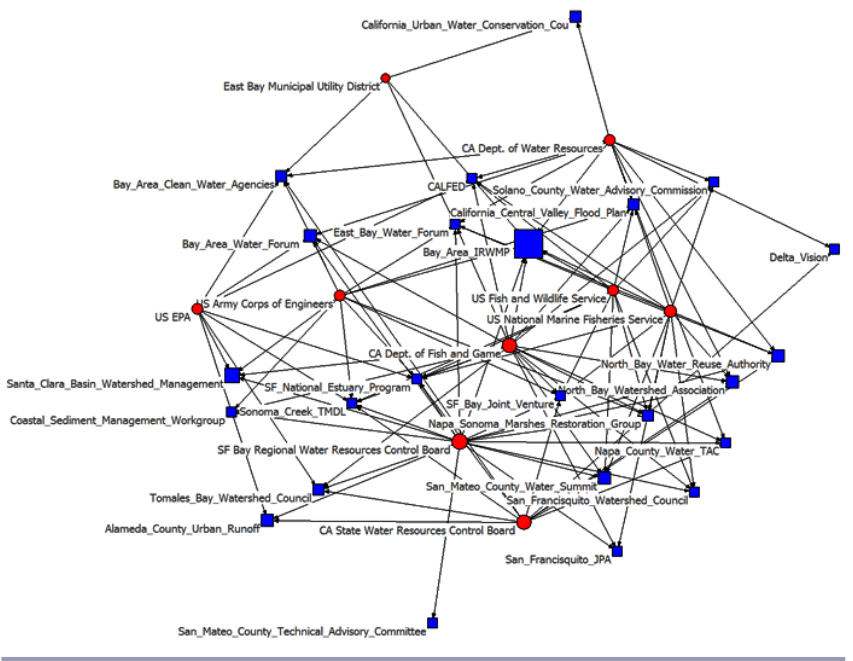

Fig. 4. Degree distributions for actors and institutions.
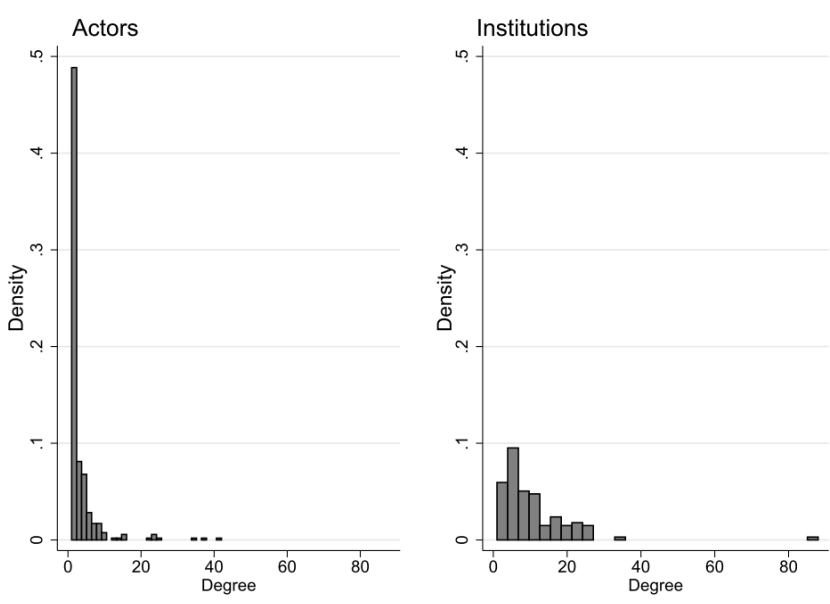

Figs. 5 and 6 report several standard measures of centrality for bipartite networks sorted by actor and institution type: normalized degree, normalized betweeness, and normalized eigenvector centrality. Degree is simply the number of connections, betweeness is the number of connections that flow through a particular node, and eigenvector centrality is higher when an actor is connected to institutions that are well-connected themselves (and vice versa).

Table 2 presents ERGM parameter estimates for each of the four model types (Table 1), where very high-degree nodes (hubs) were treated as exogenous and fixed to be consistent with the data (Robins and Lusher 2013). There was one institution with a degree greater than 80 (IRWMP), and eight federal and state agencies with degrees greater than 20 . When these connections are fixed, the resulting variation in the graph distributions is due to network activity away from the hubs. This is one way to control for highdegree nodes that are possible artifacts of data collection procedures, such as developing survey sample lists from previously known institutions. Fixing hubs was also necessary to obtain model convergence for the strategic decision and strategic geography models. ${ }^{[7]}$ Based on the Mahalanobis distance statistics, which measure how far away the observed network is from the center of the distribution of modeled networks, the strategic geography model is clearly the best-fitting model.

Fig. 5. Centrality by actor type.

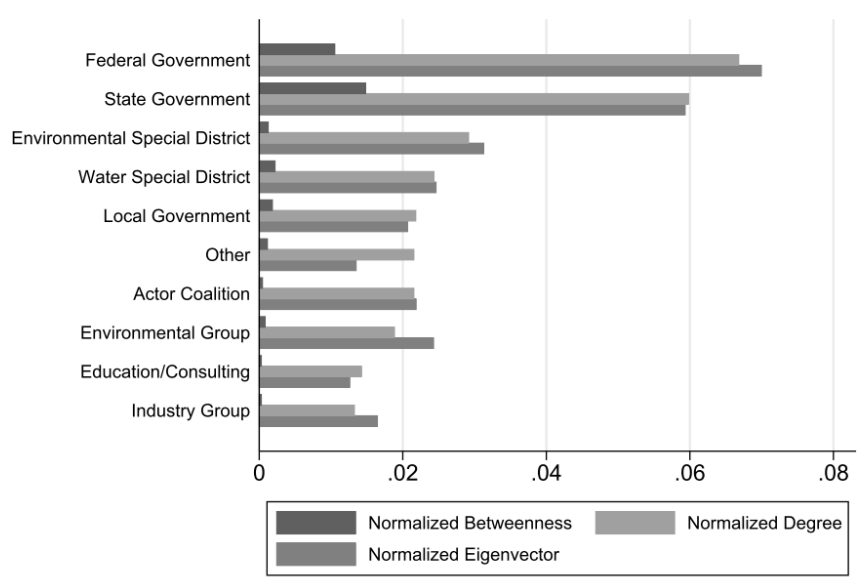

Fig. 6. Centrality by institution type.

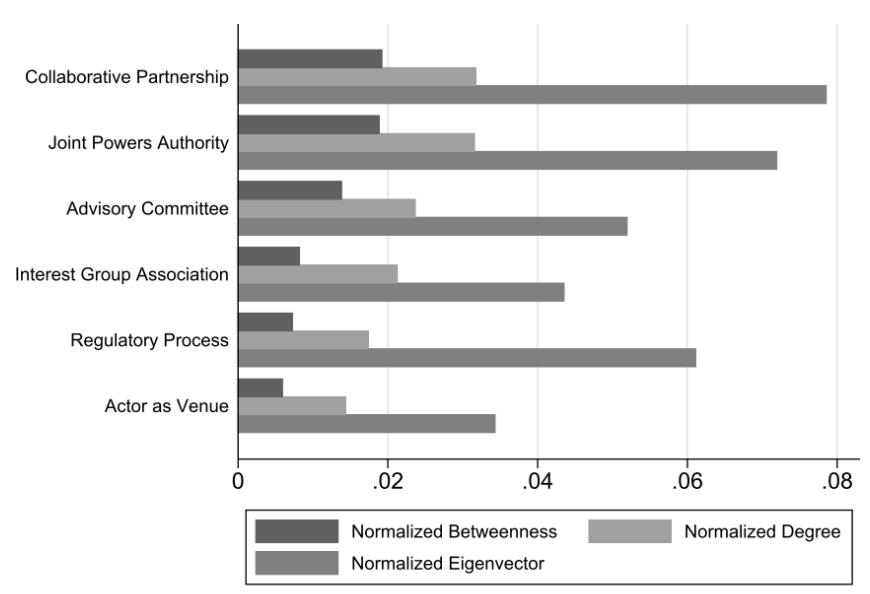

For the residual analysis, Table 3 presents $t$ statistics for actor and institution centralization and closure based on the final strategic geography model. We simulated 10 million graphs and took as our sample every 10,000th graph, giving a sample size of 1000 (see Wang et al. 2009 for more technical details). For each graph in the sample, we counted the number of various type-specific 
Table 2. Exponential random graph model (ERGM) parameter estimates

\begin{tabular}{|c|c|c|c|c|}
\hline & Naïve Actor Model & Political Capacity Model & $\begin{array}{c}\text { Strategic Decision } \\
\text { Model }\end{array}$ & $\begin{array}{c}\text { Strategic Geography } \\
\text { Model }\end{array}$ \\
\hline \multicolumn{5}{|l|}{ General Parameters } \\
\hline Density & $-3.88(0.03)^{*}$ & $-3.75(0.07)^{*}$ & $-7.01(0.35)^{*}$ & $-5.77(0.36)^{*}$ \\
\hline Centralization (actors) & - & - & $0.61(0.11)^{*}$ & $-0.21(0.11)$ \\
\hline Centralization (institutions) & - & - & $1.36(0.18)^{*}$ & $0.56(0.18) *$ \\
\hline Closure (actors) & - & - & $-0.19(0.05)^{*}$ & $-0.06(0.04)$ \\
\hline Geographic Centralization & - & - & - & $1.57(0.05)^{*}$ \\
\hline \multicolumn{5}{|c|}{ Actor Type Activity Parameters (Local Government is Excluded Category) } \\
\hline Federal Government & - & $0.45(0.15)^{*}$ & $0.43(0.16)^{*}$ & $1.82(0.18)^{*}$ \\
\hline State Government & - & $0.19(0.14)$ & $0.16(0.13)$ & $1.35(0.16)^{*}$ \\
\hline Water Special District & - & $0.13(0.09)$ & $0.12(0.09)$ & $0.42(0.10)^{*}$ \\
\hline Environmental Special District & - & $0.29(0.17)$ & $0.26(0.17)$ & $0.46(0.19) *$ \\
\hline Environmental Group & - & $-0.18(0.10)$ & $-0.16(0.09)$ & $-0.01(0.10)$ \\
\hline Industry Group & - & $-0.59(0.26)^{*}$ & $-0.50(0.23)^{*}$ & $0.05(0.29)$ \\
\hline Education/Consulting & - & $-0.40(0.18)^{*}$ & $-0.32(0.17)$ & $-0.06(0.19)$ \\
\hline Actor Coalition & - & $-0.03(0.34)$ & $-0.03(0.33)$ & $0.44(0.38)$ \\
\hline Other Activity & - & $0.07(0.48)$ & $0.11(0.43)$ & $1.33(0.54)^{*}$ \\
\hline \multicolumn{5}{|c|}{ Institution Type Activity Parameters (Collaborative Partnership is Excluded Category) } \\
\hline Interest Group Association Activity & - & $-0.22(0.10)^{*}$ & $-0.09(0.09)$ & $-0.04(0.06)$ \\
\hline Advisory Committee Activity & - & $-0.16(0.12)$ & $-0.10(0.11)$ & $-0.03(0.06)$ \\
\hline Regulatory Process Activity & - & $-0.78(0.16)^{*}$ & $-0.61(0.15)^{*}$ & $-0.36(0.12)^{*}$ \\
\hline Actor as Venue Activity & - & $-0.70(0.19)^{*}$ & $-0.47(0.16)^{*}$ & $-0.26(0.13)^{*}$ \\
\hline Joint Powers Authority Activity & - & $0.16(0.16)$ & $0.15(0.15)$ & $0.06(0.10)$ \\
\hline $\begin{array}{l}\text { Mahalanobis distance as an indicator of } \\
\text { model fit (smaller values indicate greater } \\
\text { fit) }\end{array}$ & 46,208 & 15,541 & 4,173 & 638 \\
\hline
\end{tabular}

Note: Cell entries are ERGM parameter estimates with standard errors in parentheses. All models are estimated with "exogenous hubs," with fixed degree distributions for nodes with more than 20 edges. * Reject null hypothesis of parameter $=0, p<0.05$.

Table 3. Residual analysis showing $t$ statistics $\geq 2$.

\begin{tabular}{lcc}
\hline \hline & Centralization & Closure \\
\hline Actor Types & & 4.7 \\
Federal Government & & 4.2 \\
State Government & 2.0 & 14.0 \\
Local Government & & 25.9 \\
Water Special District & 4.8 & \\
Environmental Special & & \\
District & 6.9 \\
Environmental Group & \\
Industry Group & \\
Education/Consulting & \\
Actor Coalition & \\
Other Activity & \\
Institution Types & \\
Interest Group & \\
Association & \\
Collaborative & \\
Partnership & \\
Advisory Committee & \\
Regulatory Process & \\
Actor as Venue & \\
Joint Powers Authority &
\end{tabular}

centralization and closure configurations (as in Fig. 1) to create distributions of graph statistics. We used the mean and standard deviation from the simulated distribution to calculate a $t$ statistic for the relevant observed graph statistic. Table 3 reports only extreme results with $t$ statistics $>2$.
This approach treats the strategic geography model as a null model, and analyzes whether there are significantly more or less structural configurations in the observed data than predicted by the model. Analysis of the residuals in this manner is a major benefit of ERGMs relative to more traditional linear models, where researchers usually limit interpretation to the model parameters alone.

\section{DISCUSSION}

A posited by the actor hypothesis, the visualizations and centrality statistics show that the most central actors tend to be state and federal agencies, which have broad geographic scope, expertise, information, financial resources, and political authority. The only local actor in the most central group (Fig. 3) is the East Bay Municipal Utility District, which is one of the largest urban water districts in northern California. The peripheral actors tend to be local governments and other actors with fewer political resources than the state and federal agencies.

As expected from the institutions hypothesis, central institutions consist mostly of watershed-scale collaborative groups, either covering the entire Bay-Delta or important subwatersheds. Given our study design, it is no surprise that IRWMP has the highest centrality of all nodes since our sample list started with that institution. Interestingly, some of the widely known collaborative partnerships have a lower degree, such as CALFED and Delta Vision. Although our data are not longitudinal, the survey was conducted after important changes in the Bay Area water management. Because our survey was conducted when CALFED was sun-setting and the Delta Stewardship Council was emerging, 
CALFED does not appear as central as one might expect given its prominence as an example of a collaborative partnership. This anecdote hints at the importance of studying the EG over time in order to witness changing patterns of participation as well as the decline, emergence, and longevity of different types of institutions and actors.

The higher average degree for institutions suggests that institutions play an overall more important role than actors in structuring the EG. This is intuitive because institutions are mechanisms for structuring collective decisions among many actors; it would be surprising to see more institutions than actors. On the other hand, the centrality scores and degree distributions are more highly skewed for actors than for institutions, which implies that federal and state agencies serve a stronger coordinating role relative to other actors than collaborative institutions relative to other types of institutions. One reason for this structural pattern is that government agencies are often the "hosts" for different types of institutions, using their political authority and resources to set up institutions where actors interact to make collective decisions.

The ERGMs (Table 2) reinforce the descriptive results about the structure of the EG. The best-fitting model is the strategic geography model, which introduces more complex parameters reflecting the geographic constraint hypothesis. Consistent with the geographic constraint hypothesis, the large and positive geographic centralization parameter means that actors from the same specific geographic regions are clustering around the same central institutions. The strategic geography model shows significant effects for centralization around institutions, even controlling for exogenous hubs and the average activity levels of different types of nodes.

The actor type activity parameters show five types of actors with significantly higher levels of activity than local government: federal government, state government, water special district, environmental special district, and "other" actor. As hypothesized, these actors have higher levels of political resources and capacity to coordinate activities in the EG. The institutions activity parameters suggest that regulatory processes and "actors as venues" have lower levels of activity than collaborative institutions, reflecting the inclusiveness of collaborative institutions relative to traditional regulatory institutions.

The residual analysis (Table 3 ) provides insight into the risk hypothesis by showing additional closure associated with federal and state actors, and collaborative institutions. While there is not significant general closure in the strategic geography model, the residual analysis (Table 3 ) reveals more closure around certain types of actors and institutions, and these closure processes are more extreme than for centralization. According to the risk hypothesis, this suggests that actors and institutions of particular types are involved in solving high-risk cooperation games with strong free-riding incentives. Closure processes are especially pronounced for government agencies (at each of federal, state, and local levels), water districts, and environmental groups. For institutions, the strongest results are for interest group associations and collaborative partnerships.

Our initial hypotheses did not anticipate two surprising results. First, the high level of network activity and closure observed for water and environmental special districts reflects how these actors often form competing advocacy coalitions with different water policy preferences (Jenkins-Smith and Sabatier 1993), often through the institutional vehicle of interest group associations. The more extreme closure effects around water districts are consistent with the traditional view of water districts as the more powerful and well-organized interests (Lubell and Lippert 2011). The EG is not just about coordination but also involves political power and bargaining over the distribution of the gains from cooperation.

Second, once geographic centralization is included in the strategic geography model, the sign of the actor centralization parameter becomes negative (and close to significance), and the institutional centralization parameter is much smaller. Hence, geographic centralization captures a large amount of both actor and institutional centralization, and any remaining centralization is germane to connections between regions. Taken together, the strategic geography model implies that centralization tends to occur within spatial regions, and actor activity that bridges across regions is more evenly distributed. The general actor closure parameter also becomes insignificant, which means that actors that span geographic boundaries are not especially likely to form closed structures. The EG is thus displaying multiscale properties, with actors playing different roles at the regional and local scales.

At the same time, the activity parameters for government agencies and special districts become much larger relative to local government once geographic centralization is included. State and federal agency actors, along with collaborative partnerships, are more involved in networks that span geographic boundaries, which is consistent with their broader jurisdiction and goals of policy coordination. Environmental and water special districts play boundary-spanning roles that may reflect some of the unique policy dynamics of the Bay Area. While many water districts are nested within counties, one of the most central actors in network is the East Bay Municipal Utility District, which has a service area spanning two counties, acquires water from the Sierra Nevada foothills and tributaries of the California delta, and has water conveyance systems that span the width of the Central Valley. One of the most central environmental special districts is the SF Bay Conservation and Development Commission, which regulates land development on the shoreline and riparian areas, and conducts Bay-wide land use planning. Actors with this type of broad jurisdiction achieve their policy goals through participation in multiple venues in many locations, and thus coordinate and influence actors that have a more local focus.

\section{CONCLUSION}

We sought to connect several ideas that are the heart of the literature on SES governance: coordination, networks, collaborative partnerships, polycentrism, and complex adaptive systems. The EG framework integrates these ideas, and provides a basis for developing specific hypotheses about how the structure of policy networks reflects different mechanisms of coordination. Using network analysis, we identified the types of institutions, actors, and network structures that provide coordination mechanisms in the social-ecological system of SF Bay. We expect these hypotheses will be relevant to other SESs with complex institutional arrangements, although comparative analysis is a crucial next step.

Consistent with the actor hypothesis, federal and state government agencies show the highest levels of activity, 
centralization, and closure, reflecting their control of the important political resources of expertise, information, police authority, and finances. Water districts and environmental groups are also coordinating around similar policy institutions, reflecting the politics of water management and how different interests form coalitions to bargain over policy decisions. Geography plays a crucial role in constraining this strategic behavior, with more local actors and their neighbors clustered around central institutions, while actors with a broader geographic scope are involved with more cross-boundary interactions.

Collaborative institutions play a key function in SF Bay, reflecting their inclusive approach to building multistakeholder collaboration. They are the most common type of institution, with the highest degree of network activity, and are associated with more closure than all other institutions other than interest group associations. But these results reflect how collaborative institutions are embedded within the overall set of SES governance arrangements - they function as a system. Collaborative institutions, regulations, and interest group associations all co-exist, most likely specializing in solving different types of collective-action problems. For example, the regulatory approach of the National Pollution Discharge Elimination System targets point-source pollution, while collaborative partnerships develop voluntary approaches to managing urban and agricultural nonpoint source pollution.

The network approach reiterates the multilevel, self-organized, and hierarchical structure of the complex adaptive systems that govern SESs. However, it is also critical to analyze the functional effectiveness of complex institutional arrangements to solve the underlying collective-action problems and contribute to the resilience, robustness, and adaptive capacity of SESs. To be clear, we did not directly measure function in terms of either policy outputs or outcomes. However, as with biology and ecology, structure and function are intertwined. For instance, the structural position of collaborative institutions within the SF Bay network is consistent with their hypothesized function of promoting cooperation among multiple diverse actors.

These structural characteristics reflect the purposely designed roles of these actors and institutions within the complex governance system, along with the evolution of the system to manage collective-action problems. Complex institutional arrangements are not completely chaotic - there are hierarchical structures that enable different actors and institutions to exert some control over the system. The term governance implies some capacity to manage or steer such complex systems (Klijn et al. 1995).

But observing the expected structural features is not a sufficient condition to confirm the function-more research is needed to directly observe the effectiveness of various institutions and actors. Many observers would still argue the EG presented in Fig. 2 is a highly fragmented and ineffective system. A common reaction to this situation is to recommend reducing institutional complexity and concentrating decision-making on one or a few central actors or institutions, creating a "water czar," for example. But highly centralized systems are often quite vulnerable and lack robustness. What if the central nodes are destroyed in some fashion, for example, by a change in higher level political institutions (e.g., a new governor) or budget problems? If the central actor makes a mistake, or decides to manipulate a decision in ways that benefit certain groups at a cost to the whole system, then the negative effects will ripple through the entire system.

At the other end of the spectrum, a system with completely random connections and no central coordination is also likely to fail. Hence, the "optimal" level of hierarchy and complexity is somewhere in between the highly centralized systems and the completely randomized system. This statement is obviously still quite imprecise and dissatisfying; we ultimately need to know how well a system is working and improve it. It is clear that the SF Bay policy ecology is not optimal; many collective-action problems still exist. But since the counterfactual cannot be observed, it is difficult to know whether the SF Bay system at any particular point in time is better than some alternative arrangement. The SF Bay policy ecology is a complex adaptive system that may become more effective as collaboration evolves across multiple, diverse institutions. The current level of institutional diversity provides many opportunities for collaboration, as well as policy learning and innovation in the face of complexity and uncertainty (Ostrom 2005). One way to think about this is a problem of institutional "fit"(Lebel et al. 2013) - how well does a particular set of complex institutions fit into the social ecological context in which it exists?

Ultimately, answering questions about institutional fit and functional effectiveness of complex governance requires dynamic analyses, including measuring environmental outcomes. There is no guarantee that collaboration will continue to spread in any particular policy ecology, and cooperation and conflict are likely to cycle over time. Understanding what types of institutions and network structures are related to effectiveness requires longitudinal research along with comparisons across different types of policy arenas. Such research will also be crucial for providing concrete recommendations about network management (Klijn et al. 1995) regarding how to link actors to institutions in ways that promote cooperation, adaptation, and resiliency. Understanding the structure of the policy ecology is a necessary first step to these applied policy goals, and the EG framework and network science are promising theoretical and analytical tools for this type of future research.

Responses to this article can be read online at: http://www.ecologyandsociety.org/issues/responses. $\mathrm{php} / 6880$

\section{Acknowledgments:}

Research funding supported by NSF Grant \#0921904 "Governing Complex Commons: Policy Networks in an Ecology of Games." Principal investigators Mark Lubell, John T. Scholz, and Ramiro Berardo.

\section{LITERATURE CITED}

Alston, L. J. 1996. Empirical work in institutional economics. In L. J. Alston, T. Eggertsson, and D. C. North, editors. Empirical studies in institutional change. Cambridge University Press, Cambridge, UK. 
Anderies, J. M., M. A. Janssen, and E. Ostrom. 2004. A framework to analyze the robustness of social-ecological systems from an institutional perspective. Ecology and Society 9(1):18. [online] URL: http://www.ecologyandsociety.org/vol9/iss1/art18

Ansell, C., and A. Gash. 2008. Collaborative governance in theory and practice. Journal of Public Administration Research and Theory 18(4):543-571. http://dx.doi.org/10.1093/jopart/mum032

Armitage, D. R., R. Plummer, F. Berkes, R. I. Arthur, A. T. Charles, I. J. Davidson-Hunt, A. P. Diduck, N. C. Doubleday, D. S. Johnson, M. Marschke, P. McConney, E. W. Pinkerton, and E. K. Wollenberg. 2008. Adaptive co-management for socialecological complexity. Frontiers in Ecology and the Environment 7(2): 95-102. http://dx.doi.org/10.1890/070089

Baldassarri, D., and M. Diani. 2007. The integrative power of civic networks. American Journal of Sociology 113(3):735-780. http://dx.doi.org/10.1086/521839

Bearman, P. S, J. Moody, and K. Stovel. 2004. Chains of affection: the structure of adolescent romantic and sexual networks. American Journal of Sociology 110(1):44-91. http://dx.doi. org/10.1086/386272

Berardo, R. 2014. Bridging and bonding capital in two-mode collaboration networks. Policy Studies Journal 42 (2):197-225. http://dx.doi.org/10.1111/psj.12056

Berardo, R., and J. T. Scholz. 2010. Self-organizing policy networks: risk, partner selection, and cooperation in estuaries. American Journal of Political Science 54(3):632-649. http://dx. doi.org/10.1111/j.1540-5907.2010.00451.x

Bodin, Ö., and B. I. Crona. 2009. The role of social networks in natural resource governance: What relational patterns make a difference? Global Environmental Change 19(3):366-374. http:// dx.doi.org/10.1016/i.gloenvcha.2009.05.002

Bodin, Ö., and M. Tengö. 2012. Disentangling intangible socialecological systems. Global Environmental Change 22(2):430-439. http://dx.doi.org/10.1016/j.gloenvcha.2012.01.005

Booher, D. E., and J. E. Innes. 2010. Governance for resilience: CALFED as a complex adaptive network for resource management. Ecology and Society 15(3):35. [online] URL: http:// www.ecologyandsociety.org/vol15/iss3/art35

Breiger, R. L. 1974. The duality of persons and groups. Social Forces 53:181-190. http://dx.doi.org/10.1093/sf/53.2.181

Burt, R. S. 1992. Structural holes: the social structure of competition. Harvard University Press, Cambridge, Massachusetts, USA.

Carlson, L., and A. Sandstrom. 2008. Network governance of the commons. International Journal of the Commons 2:33-54.

Cornwell, B., T. J. Curry, and K. P. Schwirian. 2003. Revisiting Norton Long's ecology of games: a network approach. City \& Community 2(2):121-142. http://dx.doi.org/10.1111/1540-6040.00044

Cranmer, S. J., and B. A. Desmarais. 2011. Inferential network analysis with exponential random graph models. Political Analysis 19(1):66-86. http://dx.doi.org/10.1093/pan/mpq037
Dillman, D. A. 2000. Mail and internet surveys: the tailored design method. John Wiley and Sons, New York, USA.

Dutton, W. H. 1995. The ecology of games and its enemies. Communication Theory 5(4):379-392. http://dx.doi.org/10.1111/ j.1468-2885.1995.tb00116.x

Folke, C., T. Hahn, P. Olsson, and J. Norberg. 2005. Adaptive governance of social-ecological systems. Annual Review of Environment and Resources 30(1):441-473. http://dx.doi. org/10.1146/annurev.energy.30.050504.144511

Gerber, E. R., A. D. Henry, and M. Lubell. 2013. Political homophily and collaboration in regional planning networks. American Journal of Political Science 57(3):598-610. http://dx. doi.org/10.1111/ajps.12011

Granovetter, M. S. 1973. The strength of weak ties. American Journal of Sociology 78(6):1360-1380.

Henry, A. D., M. Lubell, and M. McCoy. 2012. Survey-based measurement of public management and policy networks. Journal of Policy Analysis and Management 31(2):432-452. http://dx.doi. org/10.1002/pam.21623

Jenkins-Smith, H., and P. A. Sabatier. 1993. Policy change and learning: an advocacy coalition approach. Westview Press, Boulder, Colorado, USA.

Jones, C., W. Hesterley, and S. Borgatti. 1997. A general theory of network governance: exchange conditions and social mechanisms. Academy of Management Review 22:911-945.

Kallis, G., M. Kiparsky, and R. Norgaard. 2009. Collaborative governance and adaptive management: lessons from California's CALFED Water Program. Environmental Science \& Policy 12 (6):631-643. http://dx.doi.org/10.1016/j.envsci.2009.07.002

Kenis, P., and K. G. Provan 2009. Towards an exogenous theory of public network performance. Public Administration 87:440456. http://dx.doi.org/10.1111/j.1467-9299.2009.01775.x

Kimmich, C. 2013. Linking action situations: coordination, conflicts, and evolution in electricity provision for irrigation in Andhra Pradesh, India. Ecological Economics 90:150-158. http:// dx.doi.org/10.1016/j.ecolecon.2013.03.017

Klijn, E.-H., J. Koppenjan, and K. Termeer. 1995. Managing networks in the public sector: a theoretical study of management strategies in policy networks. Public Administration 73(3):437454. http://dx.doi.org/10.1111/j.1467-9299.1995.tb00837.x

Knight, J. 1992. Institutions and Social Conflict. Cambridge University Press, Cambridge, Massachusetts, USA. http://dx.doi. org/10.1017/CBO9780511528170

Koontz, T. M., and C. W. Thomas. 2006. "What do we know and need to know about the environmental outcomes of collaborative management?" Public Administration Review 66(s1):111-121. http://dx.doi.org/10.1111/j.1540-6210.2006.00671.x

Lebel, L., J. M. Anderies, B. Campbell, C. Folke, S. HatfieldDodds, T. P. Hughes. and J. Wilson. 2006. Governance and the capacity to manage resilience in regional social-ecological systems. Ecology and Society 11(1):19. [online] URL: http://www. ecologyandsociety.org/vol11/iss $1 /$ art 19 
Lebel, L., E. Nikitina, C. Pahl-Wostl, and C. Knieper. 2013. Institutional fit and river basin governance: a new approach using multiple composite measures. Ecology and Society 18(1):1. http:// dx.doi.org/10.5751/ES-05097-180101

Levin, S. A. 1998. Ecosystems and the biosphere as complex adaptive systems. Ecosystems 1(5):431-436. http://dx.doi. org/10.1007/s100219900037

Levin, S. A. 2002. Complex adaptive systems: exploring the known, the unknown and the unknowable. Bulletin of the American Mathematical Society 40(1):3-19. http://dx.doi. org/10.1090/S0273-0979-02-00965-5

Long, N. E. 1958. The local community as an ecology of games. American Journal of Sociology 64:251-261. http://dx.doi. org/10.1086/222468

Lubell, M. 2004. Resolving conflict and building cooperation in the National Estuary Program. Environmental Management 33 (5):677-691. http://dx.doi.org/10.1007/s00267-003-0066-6

Lubell, M. 2013. Governing institutional complexity: the ecology of games framework. Policy Studies Journal 41(3):537-559. http:// dx.doi.org/10.1111/psj.12028

Lubell, M., A. Gerlak, and T. Heikkila. 2013. CalFed and collaborative watershed management: success despite failure? Making space for the river: governance experiences with multifunctional river flood management in the US and Europe. 63.

Lubell, M., A. D. Henry, and M. McCoy. 2010. Collaborative institutions in an ecology of games. American Journal of Political Science 54(2):287-300. http://dx.doi.org/10.1111/j.1540-5907.2010.00431. $\underline{\mathrm{x}}$

Lubell, M., and L. Lippert. 2011. Integrated regional water management: a study of collaboration or water politics-as-usual in California, USA. International Review of Administrative Sciences 77(1):76-100. http://dx.doi.org/10.1177/0020852310388367

Lusher, D., J. Koskinen, and G. Robins, editors. 2013. Exponential random graph models for social networks: theory, methods, and applications. Cambridge University Press, New York, USA. http://dx.doi.org/10.1017/CBO9780511894701

McGinnis, M. D. 2011. Networks of adjacent action situations in polycentric governance. Policy Studies Journal 39(1):51-78. http://dx.doi.org/10.1111/j.1541-0072.2010.00396.x

Milo, R., S. Shen-Orr, S. Itzkovitz, N. Kashtan, D. Chkovskii, and U. Alon. 2002. Network motifs: simple building blocks of complex networks. Science 298:824-827. http://dx.doi.org/10.1126/ science.298.5594.824

Moe, T. M. 2005. Power and political institutions. Perspectives on Politics 3(2):215-233. http://dx.doi.org/10.1017/S1537592705050176

Norgaard, R. B., G. Kallis, and M. Kiparsky. 2009. Collectively engaging complex socio-ecological systems: re-envisioning science, governance, and the California Delta. Environmental Science \& Policy 12(6):644-652. http://dx.doi.org/10.1016/j. envsci.2008.10.004

North, D. C. 1990. Institutions, institutional change and economic performance. Cambridge University Press, New York, USA. http://dx.doi.org/10.1017/CBO9780511808678
O'Leary, R., C. Gerard, and L. B. Bingham. 2006. Introduction to the symposium on collaborative public management. Public Administration Review 66(s1):6-9. http://dx.doi.org/10.1111/ j.1540-6210.2006.00661.x

Ostrom, E. 1990. Governing the commons. Cambridge University Press, New York, USA. http://dx.doi.org/10.1017/CBO9780511807763

Ostrom, E. 2005. Understanding institutional diversity. Princeton University Press, Princeton, New Jersey, USA.

Ostrom, E. 2009a. A general framework for analyzing sustainability of social-ecological systems. Science 325 (5939):419-422. http://dx.doi.org/10.1126/science.1172133

Ostrom, E. 2009b. Institutional rational choice: an assessment of the institutional analysis and development framework. Pages 2164 in P. Sabatier, editor. Theories of the policy process. Second edition. Westview Press, Boulder, Colorado, USA.

Ostrom, V. 1994. The meaning of American federalism: constituting a self-governing society. Institute for Contemporary Studies, San Francisco, California.

Ostrom, V., C. M. Tiebout, and R. Warren. 1961. The organization of government in metropolitan areas: a theoretical inquiry. American Political Science Review 55(4):831-842. http:// dx.doi.org/10.2307/1952530

O’Toole, L. J., Jr. 1997. Treating networks seriously: practical and research-based agendas in public administration. Public Administration Review 57(1):45-52. http://dx.doi.org/10.2307/976691

Pattison, P., S. Wasserman, G. Robins, and A. M. Kanfer. 2000. Statistical evaluation of algebraic constraints for social networks. Journal of Mathematical Psychology 44:536-568. http://dx.doi. org/10.1006/jmps.1999.1261

Robins, G., L. Bates, and P. Pattison. 2011. Network governance and environmental management: conflict and cooperation. Public Administration 89:1293-1313. http://dx.doi.org/10.1111/ j.1467-9299.2010.01884.X

Robins, G., and D. Lusher. 2013. Illustrations: simulation, estimation, and goodness of fit. Pages 167-186 in D. Lusher, J. Koskinen, and G. Robins, editors. Exponential random graph models for social networks: theory, methods, and applications. Cambridge University Press. http://dx.doi.org/10.1017/ CBO9780511894701.015

Robins, G., P. Pattison, Y. Kalish, and D. Lusher. 2007a. An introduction to exponential random graph $\left(p^{*}\right)$ models for social networks. Social Networks 29:173-191. http://dx.doi.org/10.1016/ j.socnet.2006.08.002

Robins, G., T. Snijders, P. Wang, M. Handcock, and P. Pattison. 2007b. Recent developments in exponential random graph $\left(p^{*}\right)$ models for social networks. Social Networks 29:192-215. http:// dx.doi.org/10.1016/j.socnet.2006.08.003

Sabatier, P. A., W. Focht, M. Lubell, Z. Trachtenburg, A. Vedlitz, and M. Matlock, editors. 2005. Swimming upstream: collaborative approaches to watershed management. MIT Press, Cambridge, Massachusetts, USA.

Scharpf, F. W. 1997. Games real actors play: actor-centered institutionalism in policy research. Westview Press. 
Schneider, M., J. Scholz, M. Lubell, D. Mindruta, and M. Edwardsen. 2003. Building consensual institutions: networks and the National Estuary Program. American Journal of Political Science 47(1):143-158. http://dx.doi.org/10.1111/1540-5907.00010

Simmel, G. 1908. Soziologie, Untersuchungen über die Formen der Vergesellschaftung. Pages 87-408 in K. H. Wolff, editor, translator. 1950. The sociology of Georg Simmel. Free Press, New York, USA. http://dx.doi.org/10.3790/978-3-428-53725-9

Snijders, T. A. B., P. E. Pattison, G. L. Robins, and M. S. Handcock. 2006. New specifications for exponential random graph models. Sociological Methodology 36:99-153. http://dx. doi.org/10.1111/j.1467-9531.2006.00176.x

Teisman, G. R., and E.-H. Klijn. 2008. Complexity theory and public management-an introduction. Public Management Review 10(3):287-297. http://dx.doi.org/10.1080/14719030802002451

van Bueren, E. M., E.-H. Klijn, and J. F. M. Koppenjan. 2003. Dealing with wicked problems in networks: analyzing an environmental debate from a network perspective. Journal of Public Administration Research and Theory 13(2):193-212. http:// dx.doi.org/10.1093/jpart/mug017

Wang, P., G. Robins, P. E. Pattison, and E. Lazega. 2013. Exponential random graph models for multilevel networks. Social Networks 35:96-115. http://dx.doi.org/10.1016/j.socnet.2013.01.004

Wang, P., K. Sharpe, G. L. Robins, and P. Pattison. 2009. Exponential random graph $\left(\mathrm{p}^{*}\right)$ models for affiliation networks. Social Networks 31(1):12-25. http://dx.doi.org/10.1016/j. socnet.2008.08.002

${ }^{[1]}$ We define policy institutions similar to the neo-institutional economics literature, where formal rules and informal norms shape collective-choice (North 1990, Ostrom 1990). Policy institutions are not equivalent to policy games; policy games occur when actors participate in institutions. The terms policy institution and policy venue are essentially synonyms because actors strategically select to participate in different institutions. The process of collective-choice that occurs in a given institution could also be referred to as a policy or planning process, which are the terms normally used in the vernacular of real policy actors.

${ }^{[2]}$ Technically, assurance games have two coordination equilibria: one with higher and one with lower payoffs. The higher payoff equilibrium is "payoff dominant," while the lower payoff equilibrium is "risk dominant." Players will prefer the risk dominant equilibrium if they are uncertain (with some probability) about whether all players will coordinate on the payoff dominant strategy.

${ }^{[3]}$ We do not present the precise mathematical definition of the associated statistic but refer interested readers to Snijders et al. (2006) and Wang et al. (2009). The parameter is also referred to as the geometrically weighted degree distribution parameter (Snijders et al. 2006). The alternating star parameter encompasses higher order star configurations beyond those depicted in Fig. 1.

${ }^{[4]}$ Recently renamed the California Department of Fish and Wildlife.
[5] This procedure does not limit an organization to have a maximum degree of three connections to any particular policy institution. This is because the hybrid name generator allows multiple mentions of organizations; so, an organization like the California Department of Water Resources could be nominated as a participant in many different institutions. The hybrid name generator is not as good as "complete" network data that would come from a $100 \%$ survey response rate of all possible actors in the EG, but it provides data on a much larger component of the EG than if just respondent organizations were considered.

[6] We experimented with a model that included institutional closure but were unable to obtain convergent estimates. This is not surprising given that the two closure statistics are very highly correlated. A major advantage of the residual analysis is observing structural processes that are not fully captured in model parameters.

${ }^{[7]}$ We were able to obtain converged parameter estimates for the naïve actor and political capacity models without fixed high degree nodes. These models show higher positive parameter estimates for federal and state agency activity, and smaller negative activity parameters for interest group associations and advisory committees. 